Neth. J. Pl. Path. 91 (1985) 137-150

\title{
Development of a stochastic spore germination model
}

\author{
S.P. EISENSMITH ${ }^{1}$, R. RABBINGE ${ }^{1}$ and J.C. ZADOKS ${ }^{2}$ \\ 1 Department of Theoretical Production Ecology, Agricultural University, P.O. Box 430, 6700 \\ AK Wageningen, the Netherlands \\ 2 Department of Phytopathology, Binnenhaven 9, 6709 PD Wageningen, the Netherlands
}

Accepted 18 september 1984

\begin{abstract}
The concept of dose/response with logarithm of time being the dose and percent germination the response is introduced into a parallel box car model, where each spore in a population passes through its own box during its change from an ungerminated to a germinated state. Population behaviour is modelled by simulating the quantal responses of each of its members as stochastic random variables. Waiting times until germination were generated using the normal, lognormal, gamma, and exponential distributions in a computer simulation program. Good agreement with observed germination of five fungal pathogens was obtained. Methods are discussed pertaining to hypothesis testing concerning the role individuals contribute to the behaviour of the population as a whole. Two methods of handling changing temperatures are examined. Effects of inoculum density, infection efficiency, and variable temperature were incorporated into the simulation program. The stochastic model using parallel boxes offers an alternative to deterministic serial box car models which are used to mimic dispersion in time during development.

Additional keywords: computer simulation, dose/response relation, epidemiology, Coccomyces hiemalis, Venturia inaequalis, box car train.

\section{Introduction}

Knowledge of the state and rate of germination for a population of fungal spores is of major importance in the understanding and prediction of disease development. Studying the relationship of individual spore germination in response to variable environmental stimuli may be a means of elucidating population behaviour. Modelling and computer simulation techniques provide tools for exploring hypotheses put forth to explain biological phenomena, and facilitate the mimicking of population behaviour when the research objective is forecasting. We attempt in this paper to show how one can mimic spore germination for a population of spores, or develop and test hypotheses concerning the role each member contributes to the behaviour of the population as a whole. Furthermore we show that a stochastic approach may have merits in some situations as an alternative to current deterministic models. Finally, we put forth a general stochastic spore germination model capable of predicting spore germination in response to changing temperatures, based on data collected at several constant temperatures.
\end{abstract}


Data. Published data for resting spore germination of Entomophthora aphidis (Payandeh and Wallace, 1980) and for teliospore germination of Gymnosporangium juniperi-virginianae Schw. (Pearson et al., 1977) were used in this study along with unpublished data for germination of Coccomyces hiemalis Higg. conidia, Venturia inaequalis Cooke winterconidia, and Puccinia recondita Rob. ex Desm. f. sp. tritici urediospores. R. Cater, D. Rosenberger, and B. Clifford kindly supplied the germination data for the cherry, apple, and wheat pathogens, respectively. For $C$. hiemalis and $V$. inaequalis, spore suspensions obtained from pure cultures were placed on water agar plates incubated at different temperature-time duration combinations. The fraction of spores germinated was determined by counting the number of germinated spores in random areas on the petri plates and then correcting for viability by dividing all the observations by the maximum response. In the unpublished wheat pathogen study freshly collected urediospores were inoculated on plants and incubated for various times at different temperatures.

Sequential box car model. Deterministic models of spore germination were developed by Waggoner and Parlange (1974a) and De Wit and Goudriaan (1974) based on a serial box car train. These models assume that the germination of a population of spores takes time which depends upon environmental conditions. The spore population is modelled as moving through a certain number of classes (series of boxes). De Wit and Goudriaan (1974) assumed that the number of spores that germinate per day is normally distributed. Waggoner and Parlange (1974a) state explicitly that the time until germination is normally distributed and showed this to be correct in the cases they studied. Extensions of the serial box car model to include constant relative dispersion and controlled dispersion were put forth (De Wit and Goudriaan, 1974) and it was stated that this approach was only a mimicry rather than an explanatory simulation based on detailed knowledge of the physiological processes involved. Waggoner and Parlange (1974a, b) presented evidence that this type of box car model could be used to describe spore germination at changing, moderate temperatures. Similar efforts by Rabbinge (1976) have been made in applied entomology demonstrating the use of the mimicking procedure in a model of red spider mite (Panonychus ulmi Koch) populations in fruit trees. To test for compensation during development (a short larval period being compensated by a long nymphal stage) or auto-correlated development (a fast larval period being followed by a fast nymphal period) individual mites were studied, but these phenomena were not found. In fungi differences between individual spores may have considerable effects on their chances to survive, especially with alternating wet and dry or hot and cool environments.

Parallel box car model. To take into account these individual differences and to increase flexibility in the method a parallel box car model has been developed, i.e. each spore passes through one box or stage, from ungerminated to germinated, producing a quantal (yes/no) response. The population of spores is visualized as a parallel group of boxes with each spore going through its box at a different rate. The underlying assumption is that the time until germination for each spore is a stochastic random variable. 
To investigate whether or not the hypothesis that the time until a spore germinates is a normally distributed random variable, the data for the cherry and apple fungi were transformed to a probit scale to see if linearity resulted. In probit analysis it is common to use either the natural logarithm or the reciprocal of the stimulus to predict quantal responses (Finney, 1952). Therefore the data were transformed accordingly and straight lines fitted to each of the temperature sets for both the cherry and apple pathogens. Other data from the literature were tested to see if one of these approaches could have wider application. The mean or median and standard deviation of the normal and lognormal distributions were estimated by using probability paper, or obtained using regression equations to calculate the times corresponding to probit values of 5.0 (mean or median) and 4.0 (used to calculate standard deviation). The gamma distribution and a special form of it, the exponential distribution, were fitted to the spore germination data of $C$. hiemalis and $E$. aphidis. The parameters for the gamma and exponential distributions were estimated using non-linear regression with equal weights.

Hypothesis testing. Four hypotheses were compared for the E. aphidis germination data using the coefficient of determination statistic from linear regression as a measure of lack of fit. The first hypothesis that germination is a linear process involved no transformation of the data. The Box-Cox (1964) transformation of the dependent variable in the form:

$\mathrm{y}^{(a)}$ is defined as: $\begin{cases}\frac{\mathrm{y}^{a}-1}{a} & \text { when } a \neq 0 \\ \log (\mathrm{y}) & \text { when } a=0\end{cases}$

was used for testing the other three hypotheses. A value of $a=1.0$ corresponds to the hypothesis that time untii germination is normally distributed, a value of $a=0.0$ corresponds to the hypothesis that time until germination is lognormally distributed, and a value of $a=-1.0$ corresponds to the hypothesis that the rate of germination is normally distributed.

Temperature effects. Two approaches for modelling temperature effects were considered: 1) multiplying the germination rate by a temperature dependent factor or 2) changing the parameters of the underlying distribution as the temperature changes and adjusting each spore's germination (Keitt et al., 1937) were used along with the unpublished data from $\mathrm{R}$. Cater to find a temperature multiplication factor. A relative (0-1) factor was obtained by dividing all the responses by the maximum response. A second method to obtain a relative (0-1) temperature factor was examined. The equation: $Y=1.0-\mathrm{e}^{k^{\bullet} T F}$ was used to correct for the error involved at time durations where the response curve becomes flat near optimal temperatures. In this method the temperature factor $(T F)$ at $20^{\circ} \mathrm{C}$, for example, is arbitrarily set to 1.0 and the equation is solved for $k$ using the proportion germination observed at $20^{\circ} \mathrm{C}$ for $Y$. This value is then used with the fraction germinated at the other temperatures to find the corresponding temperature factors. The resulting data points were then described with a non-linear function. The function:

$Y=\mathrm{B}_{1} *\left(T-\mathrm{B}_{2}\right)^{\mathrm{B}_{4}} *\left(\mathrm{~B}_{3}-T\right)^{\mathrm{B}_{5}}$

Neth. J. Pl. Path. 91 (1985) 
has proved suitable for modelling temperature relationships (B. Hau, personal communication). Parameters $B_{2}$ and $B_{3}$ correspond closely to the minimum and maximum temperatures permitting growth, respectively. An alternative approach to multiplying the germination rate of each spore by a factor was investigated. This method involved changing the parameters of the stochastic distribution in relation to temperature and then transforming each spore's rate to the new distribution. The median germination rate for $C$. hiemalis and $V$. inaequalis conidia at different temperatures was calculated and a five parameter non-linear function as given above was used to describe the relationship between temperature and one of the two parameters of the lognormal distribution. Linear regression analysis was used to relate the second parameter to the median.

Simulation program. A computer simulation model was written in BASIC in which C. hiemalis germination at constant temperatures was simulated by generating lognormally distributed waiting times until germination for individual spores composing the inoculum dose. The germination rates are the inverse of time until germination. The assumption is that the rates of individual spores are inherently different such that a population contains a mixture of fast and slow spores. Every hour the temperature was read and the state of each spore updated using Euler integration. Normally the time step of integration is dictated by the smallest time coefficient. As this model involves only discrete events, an individual spore germinates or not, the time step is dictated by the expected frequency and the accuracy of the forcing function. The chance of germination does not depend on the number of spores ungerminated or germinated; therefore, a feedback loop is absent and the time step of integration is arbitrarily chosen to correspond to the hourly temperature data. When a spore's state exceeded 1.0 , or in other words, when the time equal to a spore's waiting time was passed, the spore was considered to be germinated.

Actual lesion numbers per $\mathrm{cm}^{2}$ of cherry leaf tissue were simulated by incorporating the inoculum dose/infection efficiency relationships observed from greenhouse infection studies (Eisensmith et al., 1982). The model was then expanded to simulate spore germination under variable temperature regimes. Little information on the presence or absence of momentaneous reaction of spores during development is available. Most models on development presume an instantaneous reaction but absence of such a phenomenon during development of living organisms may have considerable effect in development of populations (Rabbinge, 1976). In insects and mites, examples of absence of momentaneous temperature reaction have not been shown. In seeds (Janssen, 1974), momentaneous reaction is absent under certain extreme conditions. The success of germination may however decrease when temperature varies. The assumption was made that when spores are forced to change their metabolism due to a temperature change, a delay in germination occurs. In other words each spore must pay a penalty to adjust to the new temperature. This phenomenon was modelled by arbitrarily reducing the germination rate of each spore by $80 \%$, an empirical factor which can be changed when the appropriate data are available. An additional restriction was that this rate reduction factor was applied only when the temperature change exceeded $2{ }^{\circ} \mathrm{C}$. Germination was simulated at various hypothetical temperature regimes to see if the model results were consistent with observations of Alternaria solani germination at moderate, variable temperatures (Waggoner and Parlange, 
1974b). Effect of varying temperature may be expressed in a delay of development or an increase of mortality. By delaying development (slower rates), the change to bridge has increased for individual spores and this explains the difference in cumulative number of spores germinating when varying temperatures are used instead of constant temperatures.

\section{Results}

The percent germination for $C$. hiemalis and $V$. inaequalis exhibited typical asymmetric temperature response curves (Fig. 1A, B).

Germination increased with time in a non-linear way. The apple scab fungus germinated faster and showed a higher response over a wider temperature range that the cherry leaf spot fungus. Probit transformed germination response curves for the
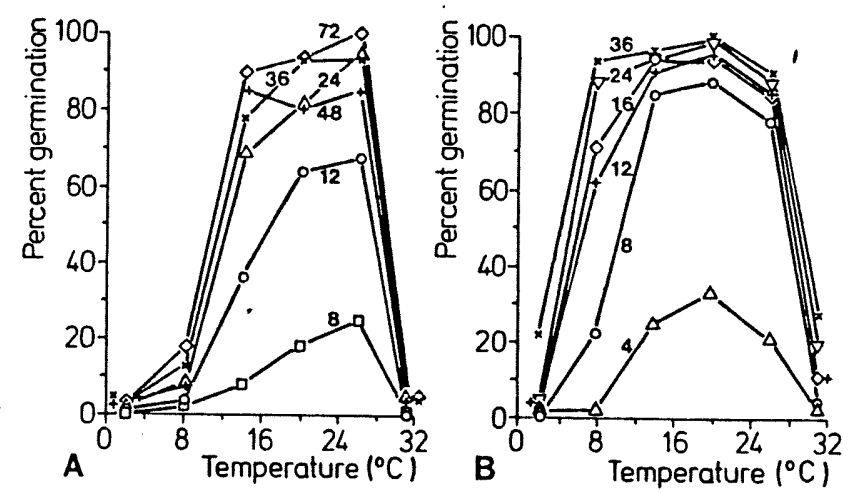

Fig. 1. Temperature response curves for germination of conidiospores of (A) Coccomyces hiemalis and (B) Venturia inaequalis. Entries: Exposure time of spores in hours. Data for $C$. hiemalis from first author and R. Cater (personal communication), for $V$. inaequalis from $D$. Rosenberger (personal communication).
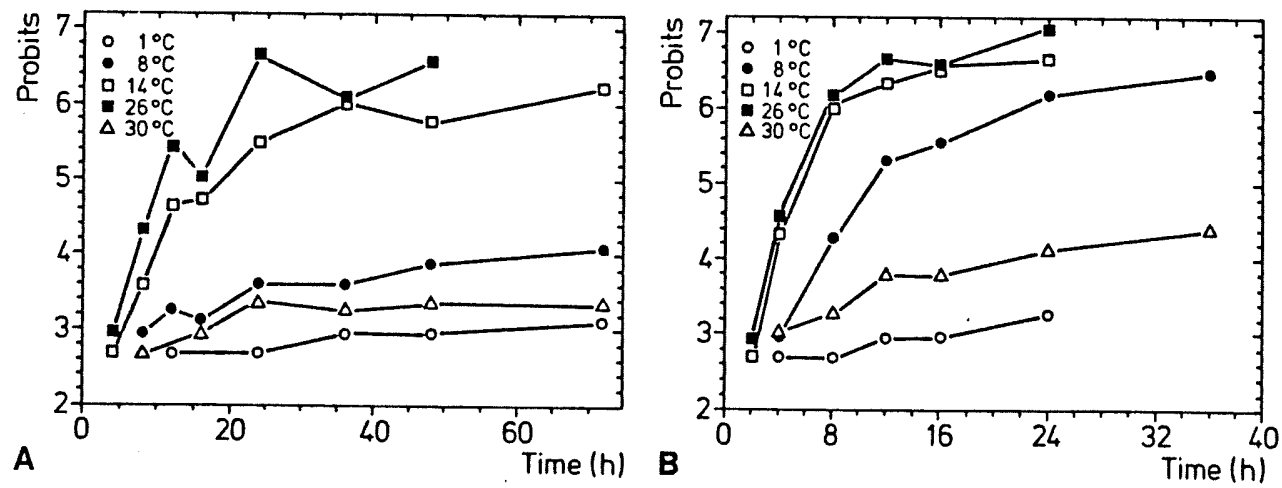

Fig. 2. Cumulative germination curves for conidiospores of (A) Coccomyces hiemalis and (B) Venturia inaequalis. Horizontal: Waiting time in hours on a linear scale. Vertical: Cumulative percentage of spore germination on a probit scale. Entries: Different temperatures.

Neth. J. Pl. Path. 91 (1985) 

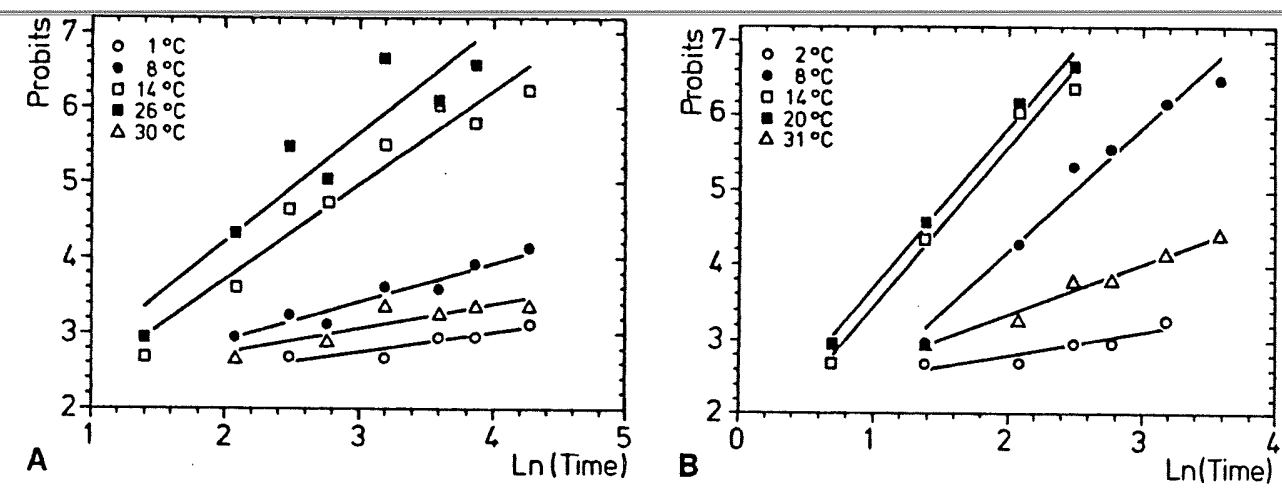

Fig. 3. Same data as in Fig. 2, after logarithmic transformation of time.

cherry and apple pathogens were used to test the hypotheses than the time until a spore germinates is normally distributed (Fig. 2A, B). Straight lines did not fit some of the temperature regimes which means that this hypothesis does not fit these data. Of interest is the statement by Waggoner and Parlange (1974a) that a Chi-square test showed their data to deviate statistically from the hypothesis of normality, but they chose to ignore this result.

Examination of alternative hypotheses involved the $\log _{e}$ transformation of time and reciprocal transformation of the fraction of spores germinated. Only the logtransformed data are shown (Fig. 3A, B). Both transformations gave suitable fits to the data indicating that either the hypothesis that the rate of germination is normally distributed, or that the time until spore germination is lognormally distributed could be appropriate to model spore germination at constant temperatures. The results of testing to see if these hypotheses may be suitable for fungi other than the above two ascomycetes showed support for both hypotheses. Since the fits were comparable, only the lognormally transformed data are presented (Fig. 4).

Plots of the relationship of temperature and the median time until germination or the standard deviation about the median for $C$. hiemalis revealed that the mean time

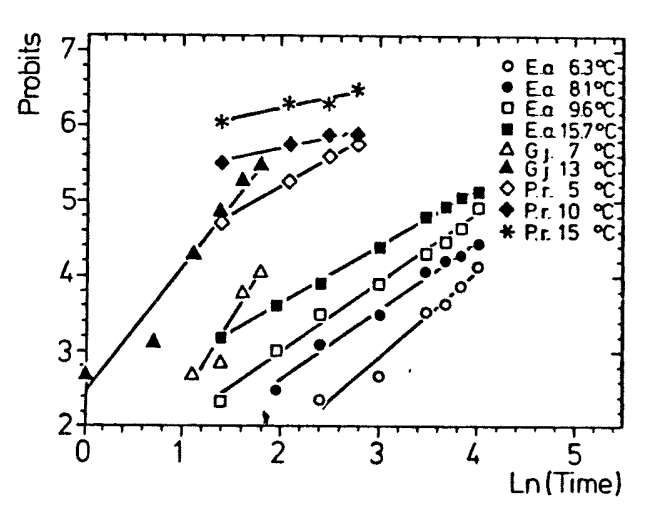

Fig. 4. Cumulative germination curves for spores of various fungi at different temperatures. Horizontal: Natural logarithm of waiting time in hours. Vertical: Probit of cumulative germination percentages.
E.a. = Entomophthora aphidis resting spores (Payandeh and Wallace, 1980).

G.j. = Gymnosporangium juniperivirginianae teliospores (Pearson et al., 1977).

P.r. = Puccinia recondita urediniospores (B. Clifford, personal communication).

Neth. J. Pl. Path. 91 (1985) 
until germination increases as one moves away from the optimum temperature and that the variance increases proportionally. In other words the typical asymmetric response curve (Zadoks and Schein, 1979) exists between the median rate of germination and temperature (Fig. 5). Similar results were found in the other data sets studied (Fig. 1). The standard deviation, the second parameter of the lognormal distribution, was easily obtained due to the proportional relationship inherent in the cherry data, where the standard deviation is approximately one third of the median (Fig. 6).

Although testing of the gamma and the exponential distributions revealed that for C. hiemalis and E. aphidis germination both distributions provided adequate fits, use of the lognormal distribution was better. Fig. 7 illustrates that over a wide range of temperatures the shape parameter is nearly 1.0 , indicating that the exponential distribution would be more appropriate for the $E$. aphidis data in view of its simplicity than the more complex gamma distribution. These data also show that the gamma scale parameter changes greatly as the exposure temperature moves outside the optimum range of 16 to $23{ }^{\circ} \mathrm{C}$. Of the four hypotheses put forth to model germination it appears that the lognormal distribution for waiting times until spore germination is appropriate to describe the quantal response of individuals in a population (Table 1).

Of the two methods tested for modelling the effects of variable temperature, the method of modifying each spore's germination rate by changing the underlying lognormal distribution parameters gave a better fit to the observed data and was subsequently used in the simulation program. However, this may be because both the data from R. Cater (Fig. 1A) and from Keitt et al. (1937) were used to find the temperature multiplication factor (TF; Fig. 8). When using only the Fig. 1A data corrected with the equation: $Y=1.0-\mathrm{e}^{\left(k^{*} T F\right)}$, which is the equation when one box is used in the box car train model, a better fit was achieved. It is somewhat remarkable that, in spite of a time span of forty years between observations, differences between workers and geographical locations, and of the fact that Cater's isolate was benomyl tolerant, the temperature factor data are similar enough to give a reasonable fit.

The variable temperature method was employed to calculate the median rate for both the old (OT) and new (NT) temperatures using the relationship of Fig. 5. When the temperatures were not the same, each spore's rate of germination was set equal to the old rate to the power of $O T / N T$. This is a consequence of the relationship from Fig. 6 and the standard lognormal transformation: $Z=\left(\ln \left(x_{\mathrm{i}}\right)-\mathrm{u}\right) / \mathrm{s}$.

Results of three computer simulation runs for constant temperatures showed good agreement to the original observations (Fig. 9). This is by no means a validation, but just a verification that the model is capable of reproducing the major time and temperature effects observed. A reasonable agreement of observed versus predicted lesion numbers was achieved when the model was used tot simulate lesion numbers for continuous wet periods at $20^{\circ} \mathrm{C}$ for different inoculum densities (Fig. 10). A statistical goodness of fit test could not be performed because the inoculum densities used in the experiments were not always precisely determined (Eisensmith et al., 1982).

Simulation of percent germination under hypothetical temperature regimes (Fig. 11) agreed with general conclusions made by Waggoner and Parlange (1975). When temperature changed from the optimal to a relative cold or hot temperature, the mean time until germination increased. This increased mean time was associated with increased variation. In simulation runs where spores were exposed alternatively to two temperatures which had the same median rate, a lower percent germination resulted

Neth. J. Pl. Path. 91 (1985) 


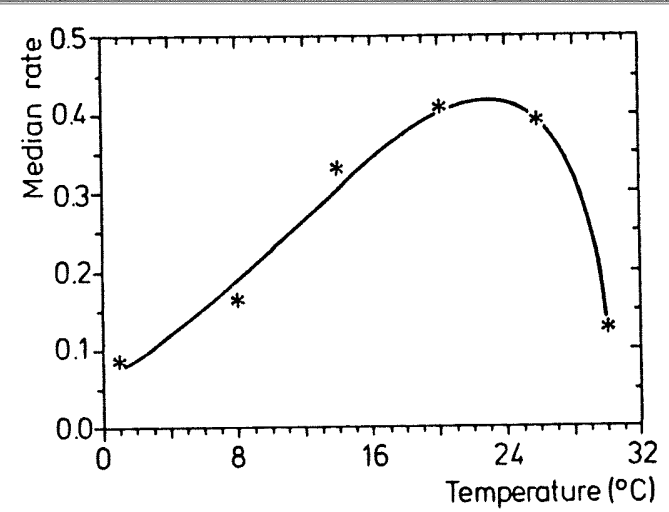

Fig. 5. Germination of Coccomyces hiemalis conidiospures. Response curve of median rate of germination (vertical) to temperature (horizontal). Compare Fig. 3 A.

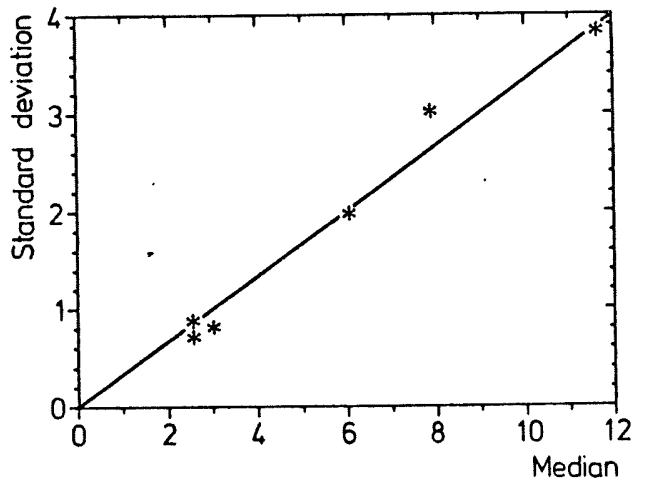

Fig. 6. Germination of Coccomyces hiemalis conidiospores. Horizontal: Median value for $\ln (t)$, where $t$ is the waiting time in hours. Vertical: Standard deviation of $\ln (t)$. Compare Fig. 3A.

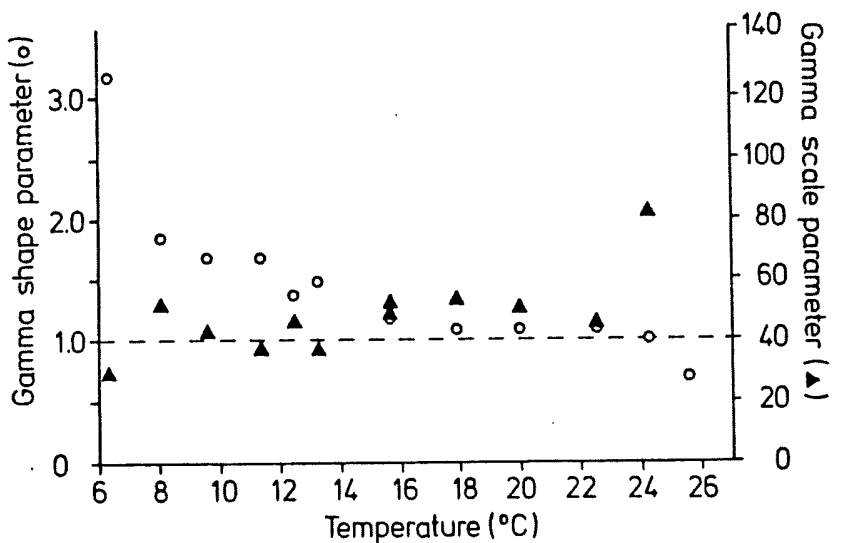

Fig. 7. Germination of resting spores of Entomophthora aphidis (Payandeh and Wallace, 1980). Data as in Fig. 4 were used to calculate fitting Gamma distributions. The relation between Gamma shape and scale parameters (vertical) and temperature (horizontal) is shown. 


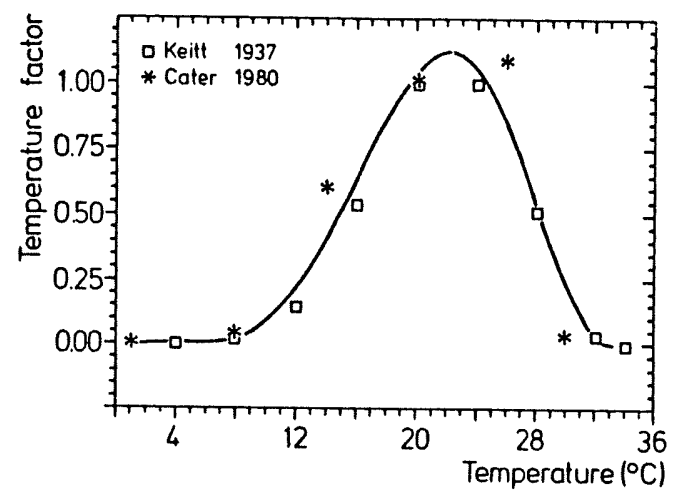

Fig. 8. Germination of Coccomyces hiemalis conidiospores. The temperature (multiplication) factor (vertical) was calculated for various temperatures (horizontal) using data from Keitt et al. (1937) and R. Cater (personal communication) as in Fig. 1A.

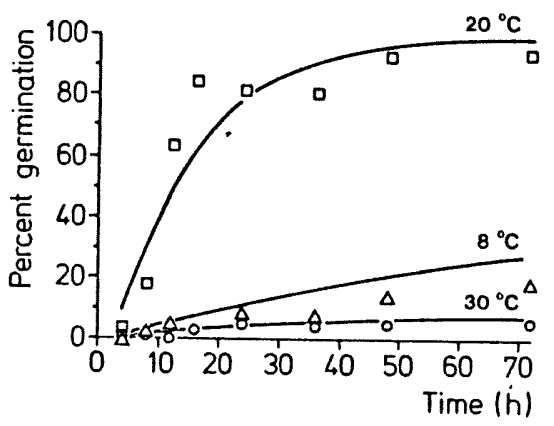

Fig. 9. Simulation of conidiospore germination of Coccomyces hiemalis. Horizontal: Germination period in hours. Vertical: Cumulative percentage of germination. Entries: Dots are observations, drawn lines render simulated values.

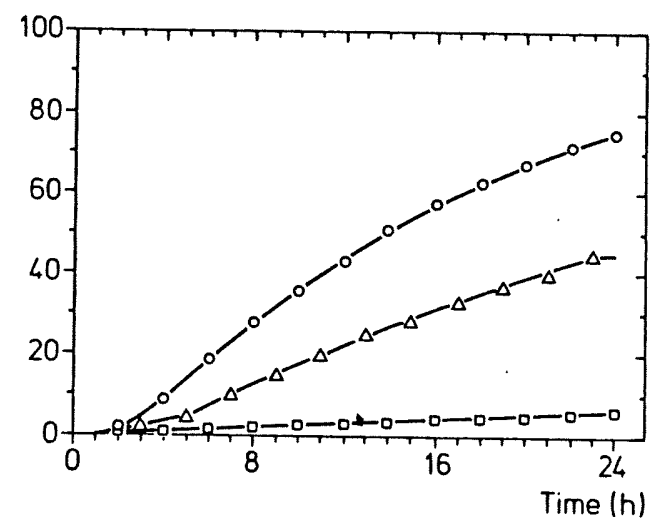

Fig. 10. Simulation of lesion development for Coccomyces hiemalis at a constant temperature of $20^{\circ} \mathrm{C}$. Horizontal: Exposure time in hours.

Vertical: Cumulative number of lesions per $\mathrm{cm}^{2}$ of cherrie leaf. Entries are different inoculum densities with equal log intervals (compare Eisensmith et al., 1982).

Neth. J. Pl. Path. 91 (1985) 
. Table 1. Coefficients of determination for four hypotheses concerning choice of appropriate stochastic distribution to describe spore germination for E. aphidis.

\begin{tabular}{|c|c|c|c|c|c|c|c|c|c|c|c|c|c|}
\hline \multirow[t]{2}{*}{ Hypothesis } & \multicolumn{13}{|c|}{ Temperature $\left({ }^{\circ} \mathrm{C}\right)$} \\
\hline & 6.3 & 8.1 & 9.6 & 11.4 & 12.5 & 13.3 & 15.7 & 15.7 & 17.9 & 20.0 & 22.6 & 24.3 & 25.6 \\
\hline $\begin{array}{l}\text { Germination is linearly } \\
\text { related to time }\end{array}$ & 0.94 & 0.98 & 0.99 & 0.99 & 0.98 & 0.98 & 0.96 & 0.94 & 0.94 & 0.94 & 0.91 & 0.91 & 0.89 \\
\hline $\begin{array}{l}\text { Time until germination is } \\
\text { normally distributed }\end{array}$ & 0.96 & 0.90 & 0.89 & 0.91 & 0.87 & 0.90 & 0.90 & 0.87 & 0.89 & 0.90 & 0.86 & 0.87 & 0.83 \\
\hline $\begin{array}{l}\text { Ln(time) until germination } \\
\text { is normally distributed }\end{array}$ & 0.96 & 0.98 & 0.99 & 0.99 & 0.99 & 0.99 & 0.99 & 0.99 & 0.99 & 0.99 & 0.98 & 0.98 & 0.97 \\
\hline $\begin{array}{l}\text { Germination rate is } \\
\text { normally distributed }\end{array}$ & 0.86 & 0.95 & 0.91 & 0.89 & 0.93 & 0.88 & 0.88 & 0.91 & 0.88 & 0.86 & 0.89 & 0.86 & 0.90 \\
\hline
\end{tabular}



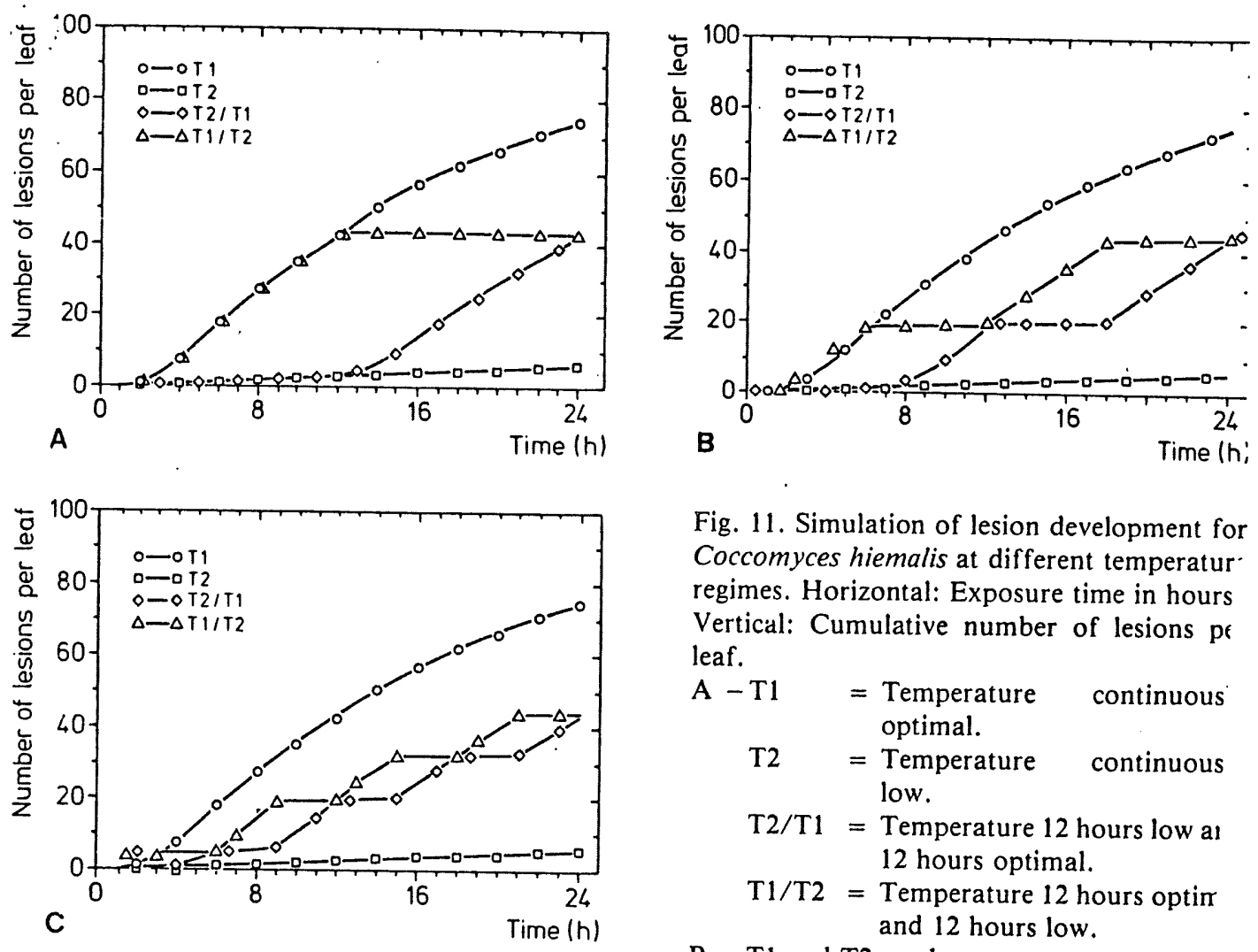

Fig. 11. Simulation of lesion development for Coccomyces hiemalis at different temperatur regimes. Horizontal: Exposure time in hours Vertical: Cumulative number of lesions $p$ leaf.
$\mathrm{A}-\mathrm{T} 1=$ Temperature continuous optimal.
$\mathrm{T} 2=$ Temperature continuous low.
$\mathrm{T} 2 / \mathrm{T} 1=$ Temperature 12 hours low a 12 hours optimal.
$\mathrm{T} 1 / \mathrm{T} 2=$ Temperature 12 hours optim and 12 hours low.
$\mathrm{B}-\mathrm{T} 1$ and $\mathrm{T} 2$ as above.
$\mathrm{T} 2 / \mathrm{T} 1$ = Alternating temperatures, low and $6 \mathrm{~h}$ optimal.
$\mathrm{T} 1 / \mathrm{T} 2=$ Alternating temperatures, optimal and $6 \mathrm{~h}$ low.
$\mathrm{C}-\mathrm{T} 2 / \mathrm{T} 1=$ Alternating temperatures, low and $3 \mathrm{~h}$ optimal.
$\mathrm{T} 1 / \mathrm{T} 2$ = Alternating temperatures, optimal and $3 \mathrm{~h}$ low.

than what would have occurred at either constant temperature. The results in Fig. 11 illustrate that spores exposed first to an optimal temperature and then to a cold temperature germinate better than when the temperatures are reversed.

\section{Discussion}

A complete discription of spore germination has to include at least three factors: 1) rate of germination, 2) variation about the mean rate, and 3) the total fraction of germinated spores achieved. The apparent plasticity of a spore population lies in the ability of individual spores to change internally within a short time period. A stochastic simulation approach shows how discrete quantal germination responses of individual spores can produce the continuous sigmoid population response as described by Neth. J. Pl. Path. 91 (1985) 
Zadoks and Schein (1979). Waiting times until germination depend of course greatly on the operational definition of when a spore is germinated. The choice of which distribution to use to describe these waiting times provides flexibility and a means of testing hypotheses.

It appears that distributions other than the normal distribution can be used to describe waiting times until the individual spores germinate. Thornley (1977) reported than the gamma distribution provides an appropriate function to model the times required to complete a biological process. The gamma function is mathematically complex and its use is based on three assumptions which may not hold. The underlying assumptions are: 1) that the process had ' $n$ ' sequential stages, 2) with the same linear rate constant to be used between any two stages, and 3 ) that the waiting times are independent and exponentially distributed. As the number of stages gets large, the gamma distribution approaches a normal distribution; however, most workers use fewer than fifteen stages but assume a normal distribution (Waggoner and Parlange, 1974a; De Wit and Goudriaan, 1974). When the shape parameter of the gamma distribution has a value of 1.0, the gamma and the exponential are the same. Therefore the exponential decay model of ungerminated seeds by De Wit and Goudriaan (1974) may be a useful simplification of the gamma distribution. Our results with a gamma shape parameter of nearly 1.0 support this idea.

As a means to decide which hypothesis to use, i.e. which distribution may be the most suitable to the data, weighted least squares or a Chi-square goodness of fit test may be employed. Because most researchers report only the fraction of spores germinated for a treatment and not both the actual number germinated and counted, equal weights must be used in the regression analysis and thus statistical discrimination power is lost.

Stochasticity should be introduced in mathematical models when there is a specific need for it. This need may be caused by the presence of curvilinear relationships between state variables and stochastic response variables (Fransz, 1974; Rabbinge and Carter, 1983), or by a clear interest in the variation of biological processes. When one of these reasons is not present, stochasticity could be omitted from simulation models.

As germination shows clear dispersion in time due to the stochastic character of germination time and as the consequences of neglecting dispersion in time are considerable, dispersion in time should be introduced in detailed models of polycyclic epidemics. This allows the modeller to examine both the most likely response, and also the inherent variation in the process. Modelling is inexact, always limited by constraints of time and money, human perception of reality, and the goal of simplicity, but simplification to the point of mean responses is acceptable only when the underlying assumptions are valid.

Using log time as a dose in the dose/response context may be applied in cases where knowledge of the distribution of times for biological development is required. The method appeals to biological intuition, is simple, flexible, and useful for other organisms or biological phenomena. Examples are latency and incubation periods in plant pathology, germination of seeds and time to flowering in botany, and maturation of insects in entomology.

The usefulness of the present germination model is multifaceted. It allows for the study of the effect of inoculum density, infection efficiency, variable environment, and differential responses of individual spores. For example, the idea that fast-germinating 148

Neth. J. Pl. Path. 91 (1985) 
spores also are the first to die at lethal temperatures could be easily incorporated into this model. Moreover, insight can be gained concerning both the mean response and how the variation about the mean changes with time. The model presented here is by no means explanatory. We only hope to show an alternative method to the deterministic serial box car train model for mimicking spore germination.

\section{Acknowledgement}

We would like to greatly acknowledge the many hours of statistical consultation provided by Dr M.A.J. van Montfort. The senior author received a fellowship from the International Agricultural Centre, Wageningen, the Netherlands.

\section{Samenvatting}

\section{Ontwikkeling van een stochastisch sporekiemingsmodel}

Het concept van dosis/response met de logaritme van tijd als de dosis en het percentage gekiemde sporen als response is geïntroduceerd in een model met parallelle boxcars, waarbij iedere spore zijn eigen boxcar bezit bij de overgang van de ongekiemde naar de gekiemde toestand. Het populatiegedrag is gemodelleerd door de kwantale responsie van iedere spore als stochastische variabele te hanteren. Wachttijden tot kieming werd gegenereerd uit de normaal, lognormaal, gamma en exponentiële verdeling die in het computerprogramma aanwezig waren. Er werd goede overeenkomst gevonden tussen gesimuleerde en waargenomen kieming bij een reeks van vijf pathogene schimmels. Verschillende hypothesen over de rol van individuele sporen voor het gedrag van het totaal werden getoetst en het effect van variabele temperatuur, inoculumdichtheid en infectie-efficiëntie werd nagegaan. Het stochastische model met parallelle boxcars is een goed alternatief voor de boxcars die in serie zijn geplaatst teneinde dispersie in tijd of ruimte na te bootsen, wanneer er verschillen in reactie tussen individuele sporen bestaan.

\section{References}

Box, G.E.P. \& Cox, D.R., 1964. An analysis of transformations. J1 R. statist. Soc. Series B 26: 211-252.

Eisensmith, S.P., Sjulin, T.M., Jones, A.L. \& Cress, C.E., 1982. Effects of leaf age and inoculum concentration on infection of sour cherry by Coccomyces hiemalis. Phytopathology 72 :
$574-577$.

Finney, D.J., 1952. Probit analysis: a statistical treatment on the sigmoid response curve. 2nd ed. Cambridge Press, Cambridge (England). $256 \mathrm{pp}$.

Fransz, H.G., 1974. The functional response to prey density in an acarine system. Simulation Monographs. Pudoc, Wageningen (the Netherlands). $143 \mathrm{pp}$.

Janssen, J.G.M., 1974. Simulation of germination of winter annuals in relation to micro-climate and micro-distribution. Oecologia 4: 197-228.

Keitt, G.W., Blodgett, E.C., Wilson, E.E. \& Magie, R.O., 1937. The epidemiology and control of cherry leaf spot. Wist. agric. exp. Stn. Res. Bull. 132: 1-118.

Payandeh, B. \& Wallace, D.R., 1980. An empirical regression function suitable for modelling spore germination subject to temperature threshold. Can. J. Bot. 58: 936-941.

Neth. J. Pl. Path. 91 (1985) 
Pearson, R.C., Aldwinckle, H.S. \& Seem, R.C., 1977. Teliospore germination and basidiospore formation in Gymnosporangium juniperi-virginianae: a regression model of temperature and time effects. Can. J. Bot. 55: 2832-2837.

Rabbinge, R., 1976. Biological control of fruit-tree red spider mite. Simulation Monographs. Pudoc, Wageningen (the Netherlands). $228 \mathrm{pp}$.

Rabbinge, R. \& Carter, N., 1983. Application of simulation models in the epidemiology of pests and diseases; an introductory review. Bulletin SROP, 1983/VI/2: 18-30.

Thornley, J.H.M., 1977. Germination of seeds and spores. Ann. Bot. 41: 1363-1365.

Waggoner, P.E. \& Parlange, J.Y., 1974a. Mathematical model for spore germination at changing temperature. Phytopathology 64: 605-610.

Waggoner, P.E. \& Parlange, J.Y., 1974b. Verification of a model of spore germination at variable, moderate temperatures. Phytopathology 64: 1192-1196.

Waggoner, P.E. \& Parlange, J.Y., 1975. Slowing of spore germination with changes between moderately warm and cool temperatures. Phytopathology 65: 551-553.

Wit, C.T. de \& Goudriaan, J., 1974. Simulation of ecological processes. Simulation Monographs. Pudoc, Wageningen (the Netherlands). 159 pp.

Zadoks, J.C. \& Schein, R.D., 1979. Epidemiology and plant disease management. Oxford University Press, New York. 427 pp. 